Article available at nttp://Www.parasite-journal.org or nttp://dx.dol.org/10.1051/parasite/200108s2147

\title{
Clinical appraisal of PATIENTS AND Detection OF SERUM ANTIBOdies BY ELISA AND CIA TESTS IN LATE PERIODS OF TRICHINELLA SP. INVASION
}

KOCIĘCKA W.*, BRUSCHI F.**, MARINI C.***, MROZEWICZ B.* \& PIELOK L.*

\begin{abstract}
Summary :
Results of our studies using ELISA and competitive inhibition assay $(C \mid A)$ tests fully confirmed the previously experienced trichinellosis and reflected persistent stimulation of antibody production due to the antigen release from Trichinella larvae, which had survived longer and undergone gradual destruction in the muscles. The studies proved that the tests complement each other, yielding concordant results in $86.7 \%$ of cases. Due to its higher specificity, the CIA test can help in interpreting pathological signs/symptoms and in evaluating humoral response activity at late and distant in time periods following the invasion.
\end{abstract}

KEY WORDS : trichinellosis, clinical appraisal, antibodies.

$\mathrm{F}$ or several years, opinions of clinicians on the late stage of trichinellosis and on its sequelae have been controversial. Fragmentary and technically imperfect serological studies have hampered in the past interpretation of the immune response. Later, studies of several authors (Fröscher et al., 1988; Harms et al., 1992; Marinculič et al., 1994; Kocieçka et al., 1997; Pielok, 2000), based on clinical studies and ELISA tests confirmed the presence of antibodies against Trichinella sp. antigen and their relation to the previous Trichinella invasion. However, till now no comparative immuno-serological studies were performed using ELISA tests and the more specific competitive inhibition assay (CIA) (Ivanoska et al., 1989; Marini et al., 1993; Medori et al., 1997). Confirmation of specificity of the antibodies is important to define the extent of humoral immune reactivity after surviving trichinellosis, to interpret properly the clinical pathology and to shape future management. Present studies aimed at comparing results of the ELISA and CIA tests in patients at various later stages following Trichinella invasion.

\footnotetext{
- Clinic of Parasitic and Tropical Diseases, University of Medical Sciences, Przybyszewskiego 49, Poznañ, Poland.

“ Dipartimento di Patologia sperimentale, B.M.I.E., Sez Patologia Generale, Via Roma 55, Pisa, Italy.

*** I.Z.S. dell'Umbria e delle Marche, Via Salvemini 1, Perugia, Italy. Correspondence: W. Kocieçka.

Tel.: +48 618691609 - Fax: +48 618671232 .
}

\section{MATERIAL AND METHODS}

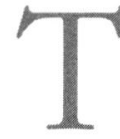
he studies were performed on 43 persons, including 40 adults (26 men and 14 women) aged 21 to 56 years (mean: $42.57 \pm 16.50$ years) and three boys, aged 12,14 and 15 years, respectively. All patients originated from Poznañ region (West Poland). Depending upon the time which elapsed following trichinellosis, the patients were included into two groups. Group I included 15 patients who reported within 71 days after infection and experienced trichinellosis one to three months earlier. Group II included 28 patients who were included into four subgroups ( $a$, $b, c, d)$. Subgroup II $a$ included nine patients controlled after three years, subgroup II $b$ comprised 10 persons examined following four years, subgroup II $c$ - six patients examined after six years and subgroup II $d$ contained only three patients examined after seven years. Clinical course of trichinellosis at its acute stage was appraised retrospectively according to Kassur \& Januszkiewicz (1969), considering also anthelminthic treatment in the acute period. Current evaluation included clinical examination, standard laboratory tests and estimation of activities of muscle enzymes, i.e. of creatine kinase (CK) and of lactic dehydrogenase (LDH), electromyographic and electroneurographic studies in lower extremity muscles (performed by Dr. J. Bombicki). In all the patients pathology of other aetiology, which might affect muscular complaints, was excluded. Antibody levels were evaluated using ELISA tests (Microtiter Kit, LMD Labs, Carlsbad) examining absorbance and rating OD of $0.0-0.39$ as a negative result, OD $0.40-1.20$ as a weakly positive result and OD higher than 1.20 as a strongly positive result. To check the results obtained with ELISA a more specific test such as CIA was performed. The plates are sensitised with the monoclonal antibody PG6B1 (specific for a $49-53 \mathrm{kD}$ antigen of Trichinella) and an antigenic preparation of Trichinella (Marini et al., 1993). The test was performed as previously described (Medori et al., 1996). Serum dilutions of 1:10-1:80 were indicative of a weakly positive result, a dilution of 1:160-1:640 corresponded to a positive, of 1:1280 
to a highly positive and of 1:2560 to extremely positive result. Biopsy of the brachial muscle was performed in eight patients, the biopsy material was examined employing parasitological and histopathochemical techniques (Dr. L. Gustowska, Dept. of Clinical Pathomorphology, UMSci, Poznań).

\section{RESULTS AND DISCUSSION}

I $\mathrm{n}$ all groups (I and II $a, b, c, d$ ) serological data obtained with ELISA (Fig. 1) and CIA (Fig. 2) were compared to each other, to the time which elapsed after acute trichinellosis and to its severity. As we can see in Table I, in Group I patients (1-3 months after trichinellosis) the result of ELISA test was negative in two patients and highly positive in 12 , ranging between 1.111 and 3.091 (MJ). In CIA test, only one patient showed low positive result (1:80), in four cases the results ranged from $1: 160$ to $1: 640$ and in 10 patients titres higher than 1:1280 were noted. Remarkably, in five asymptomatic patients and in two patients with abortive form of trichinellosis high CIA titres (> 1:640) were noted, confirming in most of the cases the high OD found with ELISA result. Thus, the clinical course failed to correlate with the extent of humoral immune response and results of ELISA and
CIA failed to correlate fully with each other. However, 13 out of 15 patients $(86.7 \%)$ resulted positive with both tests. In the remaining two cases only CIA test was strongly positive.

In the subgroup II $a$, (see Table II) including nine patients studied three years after trichinellosis, the clinical course was favourable in two cases and in the remaining cases it was moderately severe during the acute stage of the disease. ELISA results were strongly positive in eight cases, whereas high CIA titres (1:1280) were demonstrated in only three patients.

In four patients (MK, MT, $\mathrm{PH}, \mathrm{MP}$ ) parasitological testing of muscle biopsy detected 24, 14, 20 and 132 Trichinella larvae per $g$, respectively, which pointed to a relatively restricted intensity of the invasion. In three cases calcification of larvae was noted. Microscopic analysis demonstrated traits of basophilic transformation, cell infiltrates, hypertrophy of connective tissue and traits of muscular atrophy.

In the subgroup II $b$ (Table II) in all the 10 patients examined four years after the invasion, the clinical course was moderately severe (nine patients) or severe (one patient). Most of the patients of this group (six patients) showed high ELISA values. In this subgroup, high CIA titres (> 1:640) were less frequently observed.

In the six patients examined 6 years after the invasion (subgroup II $c$, Table II), who experienced a modera-

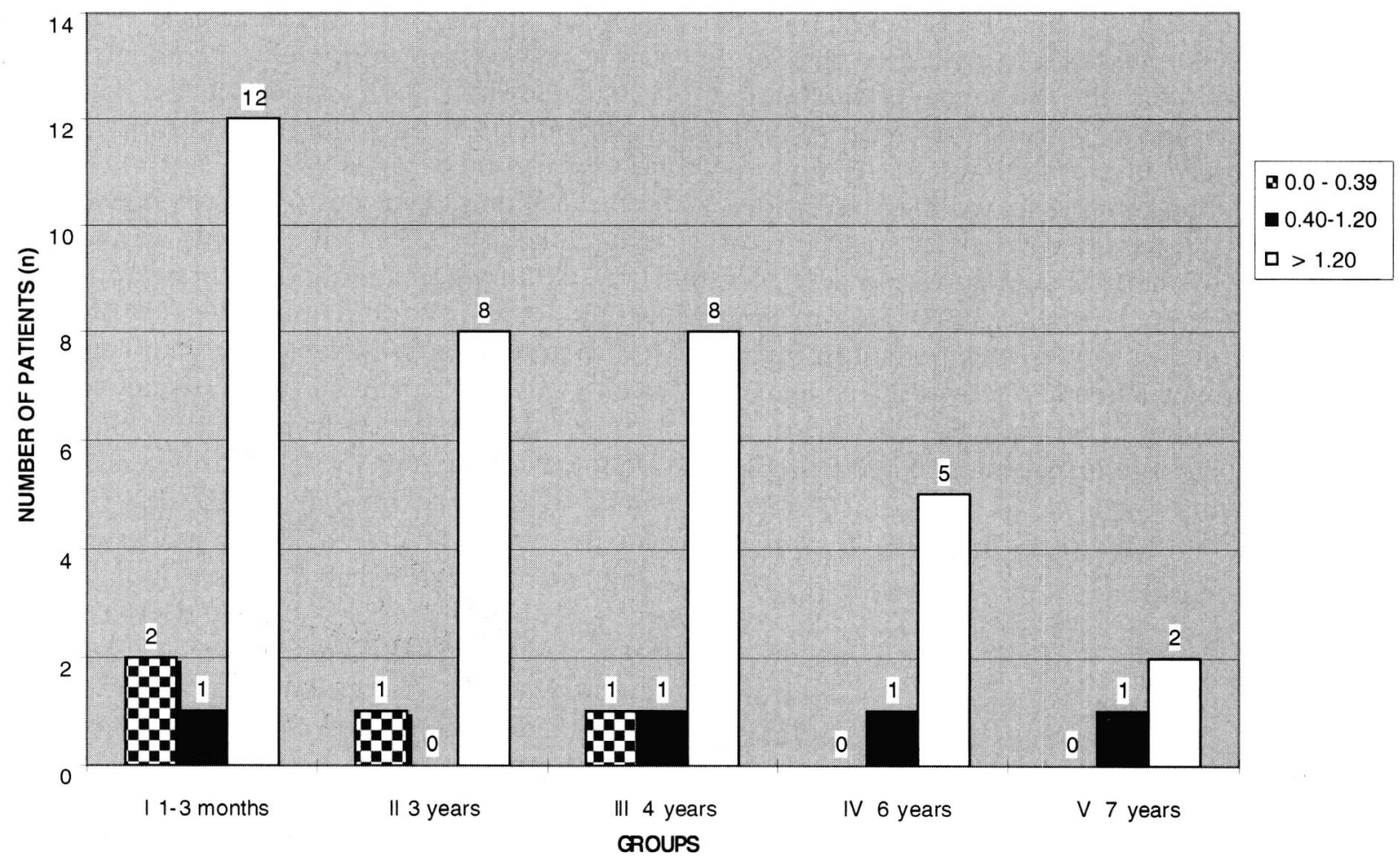

Fig. 1. - ELISA test in 43 patients with Trichinellosis history. 


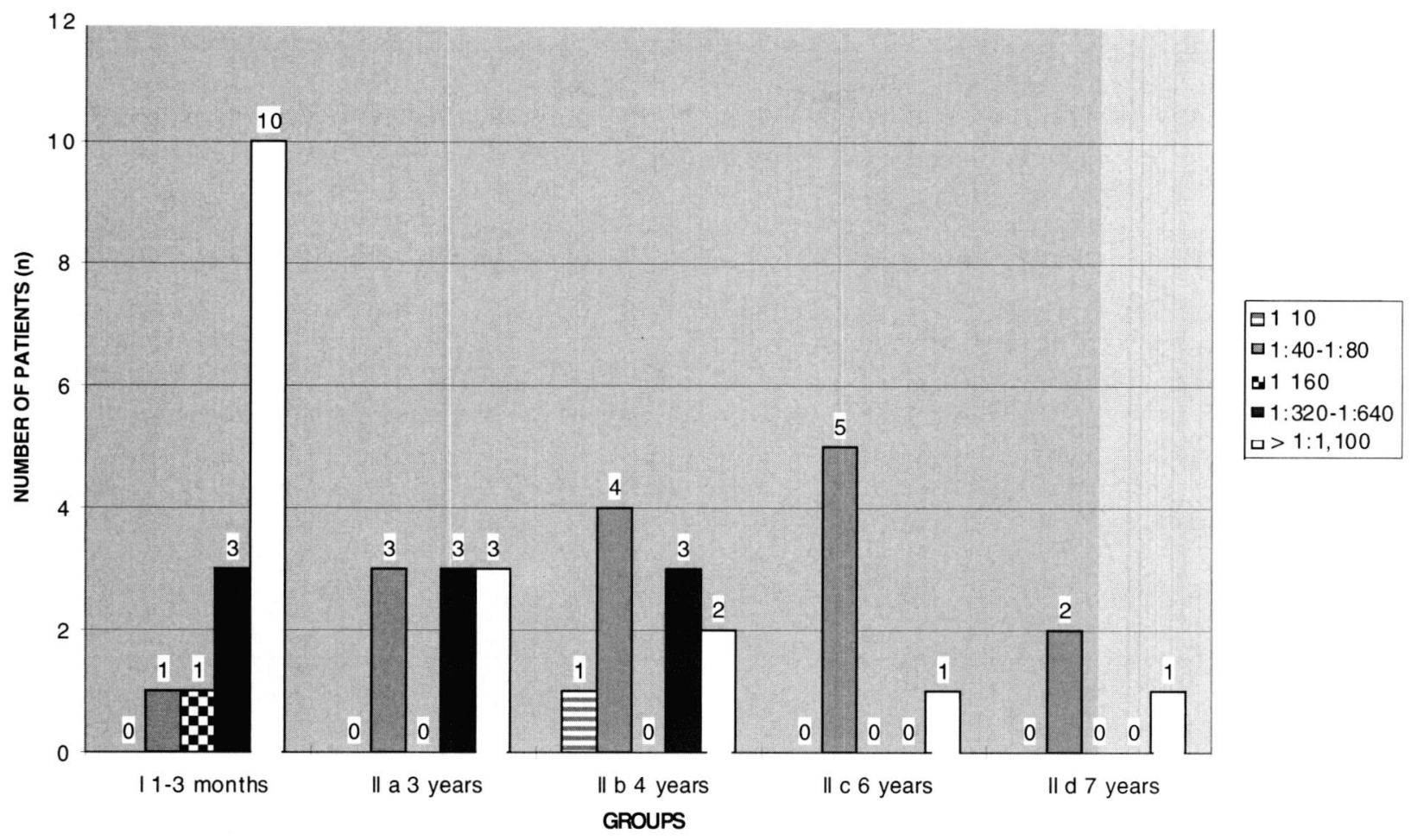

Fig. 2. - Competitive inhibition assay in 43 patients with Trichinellosis history.

\begin{tabular}{lccccc}
\hline Patients & Age & Days after acute symptoms & ELISA (OD) & CIA (titers) & Initial clinical course \\
\hline B Mr & 46 & 69 & 2.600 & $1: 640$ & moderate \\
N Mg & 37 & 28 & 2.470 & $>1: 1280$ & moderate \\
W R & 44 & 56 & 1.333 & $1: 80$ & moderate \\
M J & 47 & 66 & 3.091 & $1: 640$ & moderate \\
Z D & 44 & 90 & 2.833 & $>1: 1280$ & moderate \\
W K & 47 & 56 & 2.408 & $1: 160$ & mild \\
B Mn & 40 & 60 & 1.111 & $>1: 1280$ & mild \\
B Msz & 20 & 65 & $0.165^{*}$ & $>1: 1280$ & mild \\
B J & 42 & 58 & 1.737 & $>1: 1280$ & abortive \\
W P & 14 & 56 & 2.706 & $1: 640$ & abortive \\
K B & 43 & NE & 2.568 & $>1: 1280$ & asymptomatic \\
N M & 12 & NE & 1.641 & $>1: 1280$ & asymptomatic \\
N J & 44 & NE & 1.602 & $>1: 1280$ & asymptomatic \\
W Kt & 20 & NE & 1.957 & $>1: 1280$ & asymptomatic \\
B T & 15 & NE & $0.095^{*}$ & $1: 1280$ & asymptomatic \\
\hline
\end{tabular}

NE : not estimated.

$*$ : negative.

TABLE I. - Results of serological tests (ELISA and CIA) in 15 patients examined one to three months after the acute phase of trichinellosis.

tely severe disease, high values of ELISA were noted in two cases, moderate ones in three cases and the low result in one patient. A high titre of CIA test (> 1:1280) was noted in only one case; in the remaining five patients the titre was low (1:40 to 1:80) and failed to correlate with either the high values of the ELISA or moderately severe course of the disease.

Muscle biopsy was performed in three patients of the Group IIc (SzA, MS and KM) and in two of them Tri- chinella larvae were detected, accompanied by traits of calcification, presence of basophilic transformation of muscle cells and of cell infiltrates.

Three patients of the subgroup IId (Table II) manifested weakly positive values of the ELISA whereas CIA in only one case $(\mathrm{KJ})$ documented high titre (1:1280), the remaining two patients exhibiting low titres (1:40). The collected data showed that in patients who one to three months earlier experienced trichinellosis 


\begin{tabular}{|c|c|c|c|c|c|}
\hline Subgroup & Patients & Age & ELISA (OD) & CIA (titer) & Clinical course \\
\hline II $a$ & CE & 18 & 2.835 & $1: 2560$ & moderate \\
\hline \multirow{8}{*}{3 years after } & MK & 32 & 2.748 & $1: 1280$ & moderate \\
\hline & MT & 42 & 2.510 & $1: 640$ & moderate \\
\hline & $\mathrm{BE}$ & 52 & 2.498 & $1: 40$ & moderate \\
\hline & $\mathrm{TJ}$ & 70 & 2.466 & $1: 80$ & moderate \\
\hline & PH & 34 & 2.460 & $1: 320$ & moderate \\
\hline & $\mathrm{MZ}$ & 63 & 2.436 & $1: 320$ & mild \\
\hline & MP & 34 & 2.205 & $1: 1280$ & moderate \\
\hline & IT & 28 & 0.142 & $1: 40$ & mild \\
\hline \multirow{10}{*}{$\begin{array}{c}\text { II } b \\
4 \text { years after }\end{array}$} & BJ & 39 & 2874 & $1: 320$ & moderate \\
\hline & FR & 40 & 2.801 & $1: 40$ & moderate \\
\hline & QP & 41 & 2.700 & $1: 1280$ & severe \\
\hline & $\mathrm{KM}$ & 44 & 2.780 & $1: 320$ & moderate \\
\hline & OI & 35 & 2.417 & $1: 80$ & moderate \\
\hline & $\varnothing \mathrm{D}$ & 50 & 2.348 & $1: 1280$ & moderate \\
\hline & LM & 21 & 1.600 & $1: 320$ & moderate \\
\hline & SzJ & 42 & 1.506 & $1: 40$ & moderate \\
\hline & $\mathrm{PK}$ & 44 & 1.175 & $1: 10$ & moderate \\
\hline & $\mathrm{KW}$ & 56 & 0.100 & $1: 40$ & moderate \\
\hline \multirow{6}{*}{$\begin{array}{c}\text { II } c \\
6 \text { years after }\end{array}$} & SzA & 48 & 2.673 & $1: 1280$ & moderate \\
\hline & $\mathrm{RA}$ & 48 & 2.190 & $1: 40$ & aevere \\
\hline & MS & 22 & 1.700 & $1: 40$ & moderate \\
\hline & $\mathrm{KM}$ & 46 & 1.549 & $1: 80$ & moderate \\
\hline & RS & 20 & 1.474 & $1: 40$ & moderate \\
\hline & $\mathrm{RZ}$ & 46 & 0.956 & $1: 40$ & moderate \\
\hline \multirow{3}{*}{$\begin{array}{c}\text { II } d \\
7 \text { years after }\end{array}$} & $\mathrm{KJ}$ & 55 & 1.300 & $1: 1280$ & mild \\
\hline & RK & 57 & 1.210 & $1: 40$ & moderate \\
\hline & $\mathrm{GA}$ & 42 & 1.020 & $1: 40$ & moderate \\
\hline
\end{tabular}

TABLE II. - Results of serological tests (ELISA and CIA) in 28 patients examined three to seven years after the acute phase of trichinellosis.

(Group I) the high ELISA values, noted in $80 \%$ patients, were confirmed only in $46.6 \%$ of patients, using the CIA test. On the other hand, most of patients in Group II (subgroups $a$ and $b$ ), examined three and four years, respectively, after acute trichinellosis had still high OD with ELISA whereas high CIA titres were noted in only 30-33\% cases. This observation could indicate a lower specificity of the ELISA compared to the CIA test. The latter correlated with parasitological testing of muscle biopsies, which documented few Trichinella larvae with destruction and calcification but with presence of basophilic transformation and cell infiltrates, pointing to the still persisting pathological process.

In nine patients of subgroups IIc and IId, examined respectively six and seven years after acute trichinellosis (mostly of the moderately severe course) manifested decreasing values of ELISA and CIA tests and marked parallelism of their low values. Parasitological and pathological examination documented extensive destruction of Trichinella larvae and, in line with the observations, the attempts to biologically evaluate the larvae using PCR test failed, making taxonomic evaluation of the larvae impossible. Definition of Trichi- nella species would be important for a complete evaluation of the late invasion period, progressive degradation of larvae in the muscles and the persistent stimulation of antibody production. The phenomena may exhibit distinct time course, related to several factors: not only to the intensity of invasion and the type of treatment upon the acute stage of the disease but also to the Trichinella species involved, e.g. T.spiralis or T.britovi (Pozio et al., 1993). The problem requires further studies. Chronic character of the immune response few years after surviving trichinellosis has been confirmed by other authors (Fröscher et al., 1988; Harms et al., 1992; Marinculič et al., 1994; Kociêcka et al., 1997; Pielok, 2000). Among still ailing 33 patients, examined five years after they had suffered from trichinellosis, Marinculic and coworkers demonstrated with ELISA and immunoblotting not only IgG class (in $81.8 \%$ patients) but also IgM class (in $32 \%$ patients) antibodies.

The study of patients in the late period of trichinellosis represents an important issue for the comprehension of host-parasite relations in humans. The use of serological tests with a very high specificity could help to elucidate them. 


\section{ACKNOWLEDGEMENTS}

he authors are grateful to Dr. Leokadia Gustowska who performed pathomorphological evaluation of muscle specimens.

\section{REFERENCES}

Fröscher W., Gullota P., SAAThoff M. \& TACKmann W. Chronic trichinosis. Clinic, bioptic, serological and electromyographic observations. European Neurology, 1988, 28, 221-226.

Harms D., Binz P., Feldmeier H., Zwingenberger K., Schleehauf D., Dewes W. et al. Trichinosis: a prospective controlled study of patients ten years after acute infection. Clinical Infectious Diseases, 1993, 17, 637-643.

Ivanoska D., Cuperlovic K., Gamble H.R. \& Murrell K.D. Comparative efficacy of antigen and antibody detection tests for human trichinellosis. Journal of Parasitology, 1989, 75, 38-41.

Marini C., Piergili-Fioretti D., De Mia G.M., Grelloni V., BalZELLi B. \& Frescura T. Uso degli anticorpi monoclonali per la diagnosi sieologica della trichinosi. Atti SISVET, 1993, $47,1411-1415$.

Marinculic A., Lucinger S., Milas J., Eferberger P., MarinCULIC P., BRusChI F. et al. Persistence of immune response in patients chronically affected by trichinellosis, in: Trichinellosis Campbell W.C., Pozio E. \& Bruschi F. (eds), ISS Press, Rome, 1994, 347-351.

Medori M.C., Lemmi N., Marini C., Crotti D. \& Bruschi F. The trichinellosis risk in Umbria (Italy), a seroepidemiological study in 1000 normal subjects. Research and Reviews in Parasitology, 1996, 56, 185-189.

Medori M.C., Lemmi N., Marini C., Crotti D. \& Bruschi F. The trichinellosis risk in Umbria (Italy): Use of a competitive inhibition assay to ascertain the seropositivity, in: Trichinellosis ICT9. Ortega-Pierres G., Gamble H.R., van Knapen F. \& Wakelin D. (eds), CINVESTAV, Mexico, D.F. Mexico, 1997, 507-511.

PIELOK L. Clinical evaluation and laboratory parameters in persons with trichinellosis history. Wiadomosci Parazytologiczne, 2000 (in press).

Pozio E., Varese P., Gomez-Morales M.A., Croppo G.P., PelLICCIA D. \& BRUSCHI F. Comparison of human trichinellosis caused by Trichinella spiralis and by Trichinella britovi. American Journal of Tropical Medicine and Hygiene, 1993, $48,568-575$. 